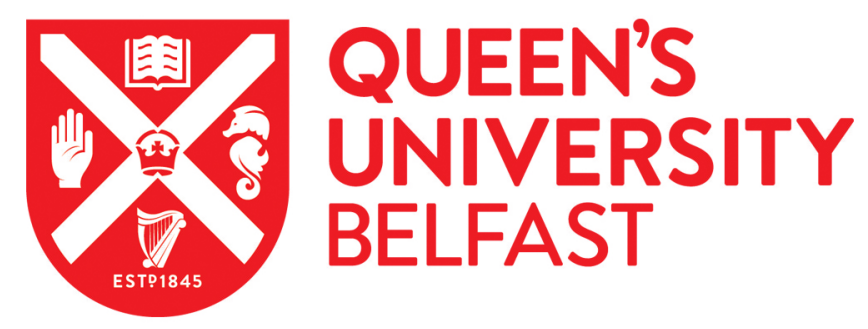

\title{
Localized intensification of arsenic release within the emergent rice rhizosphere
}

Yin, D-X., Fang, W., Guan, D-X., Williams, P., Jimenez, E. M., Gao, Y., Zhao, F-J., Ma, L. Q., Zhang, H., \& Luo, J. (2020). Localized intensification of arsenic release within the emergent rice rhizosphere. Environmental Science and Technology, 54(6), 3138. https://doi.org/10.1021/acs.est.9b04819

Published in:

Environmental Science and Technology

Document Version:

Peer reviewed version

Queen's University Belfast - Research Portal:

Link to publication record in Queen's University Belfast Research Portal

Publisher rights

Copyright 2020 ACS. This work is made available online in accordance with the publisher's policies. Please refer to any applicable terms of use of the publisher.

\section{General rights}

Copyright for the publications made accessible via the Queen's University Belfast Research Portal is retained by the author(s) and / or other copyright owners and it is a condition of accessing these publications that users recognise and abide by the legal requirements associated with these rights.

Take down policy

The Research Portal is Queen's institutional repository that provides access to Queen's research output. Every effort has been made to ensure that content in the Research Portal does not infringe any person's rights, or applicable UK laws. If you discover content in the Research Portal that you believe breaches copyright or violates any law, please contact openaccess@qub.ac.uk. 


\section{Localized intensification of arsenic release within the emergent rice rhizosphere}

Dai-Xia Yin, Wen Fang, Dongxing Guan, Paul Nicholas Williams, Eduardo MorenoJiménez, Yue Gao, Fang-Jie Zhao, Lena Q. Ma, Hao Zhang, and Jun Luo

Environ. Sci. Technol., Just Accepted Manuscript • DOI: 10.1021/acs.est.9b04819 • Publication Date (Web): 22 Jan 2020

Downloaded from pubs.acs.org on February 6, 2020

\section{Just Accepted}

"Just Accepted" manuscripts have been peer-reviewed and accepted for publication. They are posted online prior to technical editing, formatting for publication and author proofing. The American Chemical Society provides "Just Accepted" as a service to the research community to expedite the dissemination of scientific material as soon as possible after acceptance. "Just Accepted" manuscripts appear in full in PDF format accompanied by an HTML abstract. "Just Accepted" manuscripts have been fully peer reviewed, but should not be considered the official version of record. They are citable by the Digital Object Identifier (DOI®). "Just Accepted" is an optional service offered to authors. Therefore, the "Just Accepted" Web site may not include all articles that will be published in the journal. After a manuscript is technically edited and formatted, it will be removed from the "Just Accepted" Web site and published as an ASAP article. Note that technical editing may introduce minor changes to the manuscript text and/or graphics which could affect content, and all legal disclaimers and ethical guidelines that apply to the journal pertain. ACS cannot be held responsible for errors or consequences arising from the use of information contained in these "Just Accepted" manuscripts. 
1

\section{Localized intensification of arsenic release within the emergent rice rhizosphere}

Dai-Xia Yin, ${ }^{\dagger}$ Wen Fang, ${ }^{\dagger}$ Dong-Xing Guan, ${ }^{\dagger}$ Paul N. Williams, ${ }^{\ddagger}, *$ Eduardo Moreno-

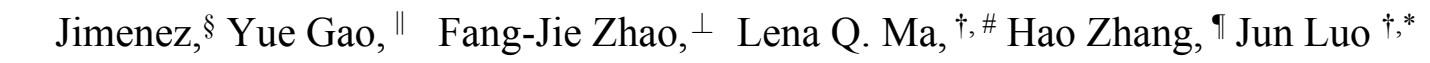

†State Key Laboratory of Pollution Control and Resource Reuse, School of the Environment, Nanjing University, Nanjing, Jiangsu 210023, China

†nstitute for Global Food Security, School of Biological Sciences, Queen’s University Belfast, Belfast BT9 5DL, Northern Ireland, United Kingdom

$\S$ Department of Agricultural and Food Chemistry, Universidad Autónoma de Madrid, E-28049 Madrid, Spain

" Analytical, Environmental and Geochemistry (AMGC), Faculty of Science, Vrije Universiteit Brussel, Pleinlaan 2, Brussels, Belgium

$\perp$ Jiangsu Collaborative Innovation Center for Solid Organic Waste Resource Utilization, College of Resources and Environmental Sciences, Nanjing Agricultural University, Nanjing, Jiangsu 210095, China

\#Soil and Water Science Department, University of Florida, Gainesville, FL 32611, USA

『 Lancaster Environment Centre, Lancaster University, Lancaster, LA1 4YQ, UK

* Corresponding authors: Jun Luo, 0086-25-89680632, esluojun@nju.edu.cn; Paul N. Williams, p.williams@qub.ac.uk 


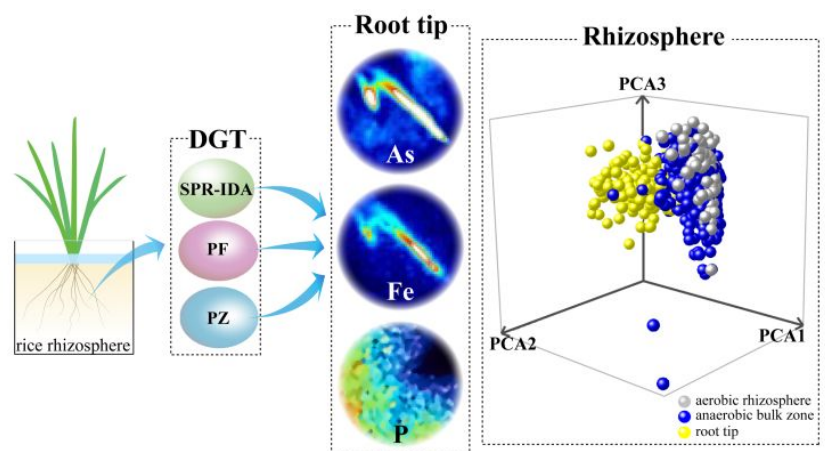


Trace element behavior in flooded/lowland rice soils, is controlled by root-zone iron oxidation. Insoluble iron species bind/capture toxic elements, i.e. arsenic. However, it was recently observed that within this territory of arsenic immobilization lies a zone of prolific iron release, accompanied by a significant flux of arsenic in close proximity to rice root apices. Questions still remain on how common this phenomenon is and whether the chemical imaging approach or soils/cultivars used influence this event. Here, three types of ultra-thin/high-resolution diffusive-gradients-in-thin-films (DGT) substrates, were integrated with oxygen-planar-optodes into a sandwich-sensor, providing a two-dimensional mapping of solute fluxes. The three DGT approaches revealed a consistent/overlapping spatial distribution with localized flux-maxima for arsenic, which occurred in all experiments, concomitant with iron mobilization. Soil/porewater micro-sampling within the rhizosphere, revealed no significant elevation in the solid phase's total iron and arsenic concentration between aerobic and anaerobic zones. Contrary to arsenic, phosphorus bioavailability was shown to decrease in the arsenic/iron flux-maxima. Rice roots, in addition to their role in nutrient acquisition, also perform a key sensory function. Flux-maxima represent a significant departure from the chemical conditions of the bulk/field environment, but our observations of a complete rhizosphere reveal a mixed-mode of root-soil interactions. 


\section{INTRODUCTION}

Arsenic (As) is a well-established poison with human carcinogenic properties.

Dietary exposure to this toxic element remains a major global health issue. ${ }^{1-3}$ Continual inputs of As enter our agri-food systems either via atmospheric deposition and/or via geological supply. ${ }^{4}$ However, this transfer has intensified with anthropogenic processes such as mining, waste incineration, fertilizer use, fossil fuel combustion, and irrigation with As-enriched water ${ }^{3}$. Importantly, As bioavailability in soil is enhanced with increasing temperature. Future climate-change scenarios predict a doubling in rice grain As by $2100^{5}$ compared to the present day. ${ }^{1}$ Plant uptake of As is accidental, occurring via transport systems that evolved for the absorbance of phosphorus $(\mathrm{P})^{6,7}$ and silicon (Si). ${ }^{8}$ As a wetland crop, rice efficiently accumulates As that is readily liberated under the highly reducing conditions of rice paddy. ${ }^{9}$ This poses, then, a serious health risk to consumers for which rice is the staple food. ${ }^{10}$

Improvements to our understanding of where and how As mobilizes and interacts with other elements, especially iron $(\mathrm{Fe})$ and manganese $(\mathrm{Mn})$, within the rice rhizosphere is needed for more targeted root-soil management. ${ }^{9,11}$ For example, release of oxygen $\left(\mathrm{O}_{2}\right)$ from the aerenchyma of rice roots into the rhizosphere can cause Fe(II) oxidation and $\mathrm{Fe}$ (hydr)oxide deposition around roots and thus decrease soluble As. ${ }^{12}$ Furthermore, Mn oxides can enhance As adsorption onto indigenous Fe (hydr)oxide phases, by promoting the oxidation of $\mathrm{As}(\mathrm{III})$ to $\mathrm{As}(\mathrm{V})$ and thus greatly reducing the porewater As concentration in the rice rhizosphere. ${ }^{13,14}$ The rooting zone in lowland 
flooded rice, though, is a particularly complex and only partially understood environment. Processes such as the release of exudates and mineral nutrient weathering, adsorption/desorption of ions from colloids, and the formation of precipitates and organic-inorganic complexes all contribute to make a patchwork of highly diverse and spatially-changeable chemistries. ${ }^{15}$ However, it is the differences in redox conditions, and the radial $\mathrm{O}_{2}$ loss (ROL) from rice roots especially that alter elemental speciation and bioavailability. ${ }^{16,17}$ For example, ROL leads to great variation in $\mathrm{pH}$, Eh, $\mathrm{Fe}(\mathrm{III}) / \mathrm{Fe}(\mathrm{II})$ quotients within micrometer ranges from root surfaces, which impact on Fe plaque formation and metal fractionation and mobility. ${ }^{18,19}$ Also, the proportion of active microbial communities in the rhizosphere are 2-20 times higher than in the corresponding bulk/field soil, ${ }^{20}$ further intensifying the chemical reactivity within the rooting zone. ${ }^{21,22}$

Encompassing a relatively small volume of soil, most rhizospheres only extend out on a millimetre scale from their associated roots. ${ }^{23}$ The reach of the rooting zone, in aquatic plants such as rice though can range further because of ROL. ${ }^{24,25}$ However, due to these zones being so redox sensitive, the chemistry in these regions is highly susceptible to disturbances arising from sampling. It is therefore necessary to develop methods that are of an appropriately high-resolution (HR), in the sub-millimeter scaling range, that can function with minimal impact on the biophysico-chemical processes occurring in situ. Traditional rhizobox and root-mat approaches for studying rhizosphere heterogeneity are challenged by the narrow spatial gradients produced by rhizosphere processes around roots, ${ }^{26}$ and for not being purpose designed/built for 
flooded soil conditions. An alternative approach is to use DGT-optode "multilayer systems". Diffusive gradients in thin films (DGT), a passive sampling technique, can measure labile metals and metalloids to predict plant availability in water, sediment and flooded soils. ${ }^{27,28}$ Two-dimensional (2D) luminescent imaging techniques (planar optodes) have been applied to measure $\mathrm{O}_{2} / \mathrm{pH} / \mathrm{CO}_{2}$ dynamics in a range of environments, which includes rhizospheres and soils. ${ }^{9}, 25$ These technologies were coupled to study the behavior of TE's in wetland soils and sediments, ${ }^{29}$ and also applied to aquatic plant rhizospheres, such as seagrass and rice. ${ }^{9,30,31}$ Consisting of a $\mathrm{pH} / \mathrm{O}_{2}$-sensitive planar optode, backed by an ultrathin $(60 \mu \mathrm{m})$ DGT layer for capturing labile TE fluxes, the HR DGT binding gel can measure/visualize metal solute chemistries with resolutions up to $\sim 100 \mu \mathrm{m} .{ }^{32}$ Not only are the individual metal/element $/ \mathrm{pH} / \mathrm{O}_{2}$ distribution images useful for interpreting the spatial lability trends, but viewed together can provide insight into the modes/mechanisms of solute release as well. ${ }^{9}$ During, these initial experiments an unexpected pulse of labile $\mathrm{As}$, along with $\mathrm{Fe}$ and lead $(\mathrm{Pb})$, was observed congruent to that of the peripherals of the aerobic rhizosphere zone. ${ }^{9}$ However, the soils used in that study, contained a low concentration of As $\left(2 \mathrm{mg} \mathrm{kg}^{-1}\right)$. Furthermore, although the rhizotrons were conditioned as wetlands, the soil used was not sourced from a rice paddy. So, whether the As mobilization trend could be replicated in an actual rice soil remains unresolved.

In the chemically dynamic environment of the rice rhizosphere, multiple elementelement interactions and diffusion-oxidation reactions would be overlaid. The DGT as a receptor to these fluxes, provides a time integrated summation of these processes. 
However, it is posited that by altering the chemistry of this sink, a different image or time lapse photograph in a single frame, ${ }^{33}$ would be captured. Therefore, in this study, sandwich-sensor solute mapping of the rice porewater was performed using three DGT binding substrates; precipitated ferrihydrite, precipitated zirconia and suspended particulate reagent-iminodiacetate (SPR-IDA), alongside standard micro-sampling of soils/waters. As a continuation of previous work, ${ }^{9}$ this experiment was designed to further test the distribution/commonalities in element bioavailability in rice rhizospheres developed in actual paddy soil, with elevated As concentrations. In addition, the scale of the solute mapping was expanded from $\sim 400 \mathrm{~mm}^{2},{ }^{9}$ to over 3000 $\mathrm{mm}^{2}$ to capture localized solute behaviors across multiple roots simultaneously. Finally, because of the close association between $\mathrm{Fe}$ and $\mathrm{P}$ mobilization, and the ability of the new DGT samplers to simultaneously measure $\mathrm{Fe}$, As and $\mathrm{P}$, it was possible to test whether the chemical hotspots around the root tips also represented sites of significant P supply.

Our hypotheses included: i) flux maxima in As, Fe mobilization at the apice zones of the rhizosphere in flooded lowland rice are common in different growing environments, ii) metal, As, P fluxes can be detected by DGT samplers configured with different binding layers, i.e. the mobilization patterns are not an artifact of a single gel type, iii) that the porewater trends are a result of either porewater diffusion and soilwater interactions, rather than general element enrichment of the soils in the aerobic rhizosphere. 


\section{EXPERIMENTAL SECTION}

Method Summary. Three different ultrathin/HR DGT configurations, with a thickness of $60 \mu \mathrm{m}$ were mounted on $2 \mathrm{D} \mathrm{O}_{2}$ optodes and exposed to preflooded and conditioned rice rhizotrons, following a previously described method. ${ }^{9}$ Furthermore, sampling of soil and porewaters was undertaken across a series of identical rice rhizotrons to observe the general trends associated with rhizosphere development, guided by $\mathrm{O}_{2}$ profiles obtained via optode measurement.

Soil and Rice Cultivation. The paddy soil was collected in the region of Extremadura (SW of Spain, $39^{\circ} 06^{\prime} \mathrm{N} ; 5^{\circ} 40^{\prime} \mathrm{W}$ ), the second biggest producer of rice in Spain. The soil, an Hydragric Anthrosol, has a loam texture, having formed in a Mediterranean climate, with hot and dry summers, $500 \mathrm{~mm}$ of annual rainfall and an aridity index of 0.5 . It has an acidic to circumneutral soil $\mathrm{pH}$, unlike other paddy regions in Spain that are predominantly basic. The soil contained $\sim 17 \mathrm{mg} \mathrm{As} \mathrm{kg}^{-1}$ (determined by ED-XRF, see SI Table S1), which is above the global average for As in soil, ${ }^{34}$ and considerably more elevated than the soils used in Williams et al. (2014) ${ }^{9}$. A compilation of relevant element concentrations can be found in the Supporting Information (SI) (Table S1). The soils were air dried and passed through a $2 \mathrm{~mm}$ sieve before packing into rhizotrons. For the rhizotron experiment, rice plants were pre-cultured in nutrient solution for two weeks before being transplanted to the rhizotrons. More specifically, after sterilization in $0.5 \% \mathrm{NaOCl}$ for $10 \mathrm{~min}$, rice seeds were soaked in deionized water overnight and germinated at $25^{\circ} \mathrm{C}$ for 2 days. Seedlings were transferred to a nylon net floating on $1 / 2$ strength Hoagland's solution in a greenhouse. After 2 weeks, rice 
seedlings were transferred to the prepared rhizotrons for a further 2 weeks growth.

DGT Preparation. In the rhizotron experiments, three different ultra-thin DGT substrates were used for chemical imaging: suspended particulate reagentiminodiacetate (SPR-IDA), ${ }^{35}$ precipitated ferrihydrite $(\mathrm{PF}),{ }^{36}$ and precipitated zirconia (PZ). ${ }^{37}$ DGT measures fluxes and interfacial concentration based on kinetic rather than equilibrium principles. The performance of ultra-thin DGT has been verified and SPRIDA gel possesses adequate adsorption capacity (e.g. Cd is $0.26 \mathrm{mg}$ ) for cations and some anions. ${ }^{35,38}$ Meanwhile, PF and PZ gel exhibit stronger adsorption capacity for anions in preference to cations. ${ }^{36,37}$ The fast uptake of the target ions to the PF (binding rate for As is $0.011 \mu \mathrm{g} \mathrm{cm}^{-2} \mathrm{~min}^{-1}$ ) and $\mathrm{PZ}$ gels (binding rate is $0.003 \mu \mathrm{g} \mathrm{cm}^{-2} \mathrm{~min}^{-1}$ ) has previously been verified. ${ }^{36,37}$ However, there are limitations for SPR-IDA resin gels, especially for anion measurement. Their performance depends on solution conditions ${ }^{35}$ and not all species, such as As(V), are captured quantitatively. ${ }^{32}$ Adsorption-desorption of As is the primary factor that impacts on the bioavailability and mobility of As in soils. Metal ligands bind with a distribution of $K$ values, resulting in a range of labilities for bound metals that is affected by the extent of binding. Although, differences in ligand-assisted dissociation of complexes in different resin layers has an important role on the binding performance, ${ }^{39}$ different binding layers also represent different sinks that could potentially alter the final chemical image based on binding characteristics. This idea was further explored in this study.

The SPR-IDA gels were prepared as described before. ${ }^{9}$ Briefly, $1 \mathrm{ml} \mathrm{SPR-IDA}$ suspension was added to $1 \mathrm{ml}$ mixture of acrylamide (40\%, BDH Eletran) and agarose- 
derived cross-linker (DGT Research Ltd., UK) (40\% acrylamide/cross-linker, 4/1). Then $14 \mu \mathrm{L}$ of ammonium persulfate $(\mathrm{BDH})$ and $4 \mu \mathrm{L}$ of $N, N, N^{\prime}, N^{\prime}-$ tetramethylethylenediamine (TEMED) (BDH Electran ${ }^{\circledR}$ ) were added. After quick mixing, the gel solution was then immediately cast between two glass plates separated by a $0.06 \mathrm{~mm}$ plastic spacer. Once cast, the glass plate was assembled and placed into an oven at $45{ }^{\circ} \mathrm{C}$ for $1 \mathrm{~h}$. Afterwards, the glass plates were separated, and the gels was placed into $0.5 \mathrm{~L}$ of ultrapure water (MQ water, Millipore, 18.2 $\mathrm{M} \Omega$ ) and allowed to fully hydrate for at least $24 \mathrm{~h}$ with water changing 3-4 times.

To prepare the PF and PZ gels, a series of ultra-thin acrylamide gels, following the same protocols as the SPR-IDA but without the binder, were cast using $0.06 \mathrm{~mm}$ thick spacers. After hydration, the gel sheets were immersed in solutions of $100 \mathrm{~mL} 0.1 \mathrm{M}$ $\mathrm{Fe}\left(\mathrm{NO}_{3}\right)_{3} \cdot 9 \mathrm{H}_{2} \mathrm{O}$ or $0.1 \mathrm{M} \mathrm{ZrOCl}_{2} \cdot 8 \mathrm{H}_{2} \mathrm{O}$ for $\mathrm{PF}$ gels $^{36}$ and $\mathrm{PZ}$ gels $^{37}$, respectively. These gels were immersed for at least $2 \mathrm{~h}$ to ensure a uniform distribution of $\mathrm{Fe}$ or $\mathrm{Zr}$ in the matrix. Afterwards, each gel was rinsed with MQ water for 1-2 s and then immersed in $100 \mathrm{~mL}$ of $0.05 \mathrm{M} 2$-( $N$-morpholino) ethanesulfonic acid (MES, biochemical, BDH) buffer solution ( $\mathrm{pH}$ 6.7) to produce a precipitation of ferrihydrite or zirconia directly into the gels. After about 40 min of shaking gels to allow complete development, the gels were rinsed several times in MQ water, and soaked in MQ water for $24 \mathrm{~h}$. Over this period the water bath was changed 5-6 times.

All preparation and processing of gels was conducted in a laminar flow bench (SW-CJ-1B, Airtech, China) within a clean room using ultraclean trace metal techniques. Before deployment, acid-washed Nuclepore membranes (Nucleopore, 
Whatman, $0.4 \mu \mathrm{m}$ pore size and $10 \mu \mathrm{m}$ thickness) were fixed between the soil and gel, to avoid particle contamination, and to act as a diffusion layer for the DGT binding gel. All binding gels were preserved in $0.01 \mathrm{M} \mathrm{NaCl}$ solution until rhizosphere deployment.

Rhizotron Experiment. The plant-soil housings used in this study had inner dimensions of $40 \mathrm{~cm} \times 10 \mathrm{~cm} \times 1.5 \mathrm{~cm}$ (height $\times$ length $\times$ width), with detachable front plates, that were filled with the sieved soils. The soils were compacted in layers to achieve a homogeneous texture with a uniform bulk density of $1.3 \mathrm{~kg} \mathrm{~L}^{-1}$. Soils in rhizotrons were carefully saturated with water using a slow-flow gravimetric irrigation system, to avoid disturbing the soil structure and to enable Nuclepore membranes (pore size is $0.2 \mu \mathrm{m}$ and thickness is $\sim 10 \mu \mathrm{m})$ to be fixed on the ventral plane of the rhizotron. The membranes help to ensure soil uniformity during DGT and planar optode deployment and protect the roots and soils from being disturbed when the rhizotron's front plates were later removed. The filled rhizotrons were then conditioned anaerobically in a water tank purged with nitrogen gas, for 2 weeks, after which, a 2-week-old rice seedling (cv. Nipponbare), was transplanted in close proximity to the front plate of each rhizotron. The planted rhizotron systems were maintained at a $30-45^{\circ}$ inclination to facilitate the root growth along the lower front windows of the devices. In total, 14 rhizotrons were prepared. The rooting/soil zones in all the replicates were kept away from light to simulate field conditions and avoid inducing microphyte growth. Plant development was monitored frequently, with root development assessed by visual inspections and $\mathrm{O}_{2}$ measurements from planar optodes (detailed descriptions are presented in the SI). At the time of sampling (4-week-old seedlings) the replicates with 
the clearest ROL profiles were selected for $2 \mathrm{D}$ solute/chemical imaging by the combined DGT/optode sampler. After the DGT/optode retrieval, the destructive sampling for porewater and subsoils in all rhizotrons was conducted as below.

Chemical Mapping. After $24 \mathrm{~h}$ deployment in the rhizotrons, the DGT gels were retrieved and rinsed with MQ water, and dried using a gel drier (Bio-Rad model 543) and then carefully fixed onto glass plates using heat-resistant double-sided adhesive tape prior to laser ablation (New Wave, Cambridge, U.K.) coupled with inductively coupled plasma mass spectrometry (NexION 300, PerkinElmer, USA) (LA-ICP-MS) analysis. Calibration and detector performance were optimized prior to commencing dry plasma tuning. The laser system, with wavelength quadrupoled to $213 \mathrm{~mm}$, was equipped with a large format ablation cell. Line scans of the gels were carried out at a spot size of $100 \mu \mathrm{m}$, scanning speed of $100 \mu \mathrm{m} \mathrm{s}^{-1}$, an interline spacing of $400 \mu \mathrm{m}$, a repetition rate of $20 \mathrm{~Hz}$, and energy output is $0.012 \mathrm{~J} \mathrm{~cm}^{-2}$. ICP-MS was used to record the elemental signals (Table S2). ${ }^{13} \mathrm{C}$ was used as internal standards to correct variations in ablation, transport, and ionization efficiency.

$\mathrm{O}_{2}$ distributions in the rhizotrons were captured using planar optode sensors. ${ }^{40}$ Procedures of optode fabrication and imaging are presented in the SI. Processing of the original DGT data was conducted firstly in Microsoft Excel 2016 and then ImageJ 1.50i, whereas optode data was processed directly in ImageJ 1.50i. Principle Components Analysis (PCA) of transects of the main images were conducted in Minitab19. 
Rhizotron Soil and Porewater Sampling. To collect soils and porewaters during

plant harvesting, we used a compartmented approach targeting bulk/field anaerobic and rhizosphere aerobic soil zones, as determined by planar optode measurements. Sampling was conducted in an aerobic cabinet (YQX-II; Longyue), purged with nitrogen $(>99.5 \%)$ to stabilize the redox conditions. Concentrations of $\mathrm{O}_{2}$ within the main chamber, which contains vessels of desiccant and deoxidizer catalyst, were $0.01 \%$ after a standard N-purge of $1 \mathrm{~h}$. Porewater were extracted by applying suction to Rhizon samplers $(0.15 \mu \mathrm{m}$ pore size, $1 \mathrm{~mm}$ outer diameter, and $8 \mathrm{~mm}$ long, No. 19.21.81, Rhizosphere Research Products, Netherlands) using syringes, after the samplers were inserted into soils and left to equilibrate for $1 \mathrm{~h}$. The collected porewaters were then acidified with high purity $\mathrm{HNO}_{3}$ and analysed by ICP-MS.

The fresh soil samples $(\sim 3 \mathrm{~g})$ were collected using a plastic spatula, then freezedried and sieved $(2 \mathrm{~mm})$. Subsamples of $0.2 \mathrm{~g}$ were digested in a mixture of $\mathrm{HNO}_{3}$ and $\mathrm{H}_{2} \mathrm{O}_{2}$ (EPA 3050B) and then element concentrations were analysed using ICP-MS, for more details on the quality assurance and quality control see the SI (Table S3).

\section{RESULTS AND DISCUSSION}

\section{Localized Intensification of As Mobilization across the Rhizosphere-Soil}

Continuum is a Common Occurrence. In support of previous observations, ${ }^{9}$ the rhizospheres formed by the seedlings were found to have a demonstrable effect on the occurrence and intensity of both $\mathrm{O}_{2}$ and element fluxes. This is clearly shown in Figures 1 and S2 (see SI), where oxygenation is sustained most effectively in the central 
rhizosphere, dissipating as the peripheries of the root zone were reached. As the interpretation here of the rooting zone is based on the optode images, a more appropriate term would be the aerobic rhizosphere $(\mathbf{O}+\mathbf{R})$. Conversely, $\mathrm{O}_{2}$ concentrations in the surrounding bulk/field soil were barely detectable, indicating the general soil environment (O-B) was anaerobic/highly reducing. The $\mathbf{O}+\mathbf{R}$ can lie in very close proximity to the root surface, but it is not exclusively so, and oxic conditions can form up to several millimetres away from roots. These aerobic pockets can be maintained by a variety of processes that include: continual radial $\mathrm{O}_{2}$ diffusion from the roots, as well as there being potentially also some $\mathrm{O}_{2}$ drawn down from the aerobic overlying waters, as the channels in the soils formed by the roots form a conduit to the surface. ${ }^{41}$

As previously observed, ${ }^{9}$ the flux images with SPR-IDA DGT illustrate a general commonality in the spatial distribution of $\mathrm{As}, \mathrm{Fe}$ and $\mathrm{Pb}$ (Figure 1 and $\mathrm{S} 2$, Table 1), but also a series of subtle differences. A key similarity was that flux maxima (FM) for all three elements converged in regions associated with root apex rhizosphere zones. One, FM1 in Figure 1c) occupied $\sim 1.5 \times 0.5 \mathrm{~cm}^{2}$ and comprised of two distinct branches. The second zone (FM2 in Figure 1c), was less prominent but exhibited similar chemical features. Interestingly, there were no flux maxima or ROL associated with the primary root in the $\mathbf{O}-\mathbf{B}$ zone, with As bioavailability around this feature actually recording a lower flux than the surrounding non-rhizosphere/anaerobic soil (Table 1). On the contrary, the $\mathbf{O}+\mathbf{R}$ appeared to have a limited impact on the bioavailability of $\mathrm{Mn}$. There was some Mn release where the Fe/As root maxima located. However, these fluxes were only slightly above background and notably less intense than the microniche 
features (Figure 1e). However, Mn was mobile, with release characterized as a widespread series of discrete hotspots, with a typical size of $0.4 \mathrm{~mm}^{2}$. Within this dispersed array of Mn microsites, four larger, roughly spherical maxima clustered in the upper soil zone (M1, Figure 1e), indicating a slightly different mode of release. Variations in oxidation rate and biological activity under flood conditions would affect Mn behavior, with a variety of microorganisms known to be capable of coupling growth to Mn oxide reduction, using $\mathrm{Mn}$ as a terminal electron acceptor. In addition to $\mathrm{Mn}(\mathrm{II})$, soluble $\mathrm{Mn}(\mathrm{III})$ or $\mathrm{Mn}(\mathrm{IV})^{42,43}$ would also be targeted by DGT, so the measurements are a multi-species summation. However, $\mathrm{Mn}(\mathrm{II})$, is a simple/hydrated species, and once formed is more stable in anoxic water than $\mathrm{Fe}(\mathrm{II}){ }^{44}$

Spatial flux patterns of Co, Ni, and Zn did not map with either the $\mathbf{O}+\mathbf{R}$ or FM rhizosphere. However, there was a clear association between the $\mathrm{Co}, \mathrm{Ni}, \mathrm{Zn}$ and $\mathrm{Mn}$ observed in a Principle Components Analysis (PCA) of a transect encompassing FM1, O+R1, and O-B1 regions (Figure 1f). The PCA, also highlights a clear differentiation in chemistries/flux characteristics between the zones (Figure 1f).

When the experiment was repeated but with a new rhizotron/seedling, a similar but less obvious series of root tip maxima for $\mathrm{As}, \mathrm{Fe}$ and $\mathrm{Pb}$ were also observed (FM3 \& FM4 in Figure 2). Again, the enhanced mobilization was constrained to the upper root zones and showed a similar pattern to that of the main fluxes in Figure 1. Fluxes of As, $\mathrm{Fe}$ and $\mathrm{Pb}$ around the tips were different from either the $\mathbf{O}+\mathbf{R}$ zone or anaerobic bulk/field soil (PCA, Figure S3). However, interestingly, for O+R2 (Figure 2), the mobilization patterns for As and Fe were different to $\mathbf{O}+\mathbf{R} \mathbf{1}$ (Figure 1) and previous 
results ${ }^{9}$ turning this region into a flux hotspot compared with the surrounding anaerobic bulk/field soil. Reasons for this could be due to the oxic zone, being less developed and more unstable than in the rhizosphere captured in Figure 1. Furthermore, trends in As and $\mathrm{Fe}$ mobilization were consistent, but $\mathrm{Pb}$ release was unconnected. Indeed, the feature $\mathbf{O}+\mathbf{R} 2$ shares many chemical similarities to the root flux maxima zones but with less intense element lability and a larger spatial coverage. Again, there were Mn hotspot maxima as well as depletion features, but they bared little relationship to the $\mathbf{O}+\mathbf{R}$ zones (Figure 1 and 2).

In another region of chemical relevance (microniche-M2; Figure 2), observed within the anaerobic bulk/field soil, the average fluxes of Fe and Mn were greater than the surrounding soil reaching up to 6.31 and $0.42 \mathrm{pg} \mathrm{cm}^{-2} \mathrm{~s}^{-1}$ respectively (baseline levels being 3.70 and $0.17 \mathrm{pg} \mathrm{cm}^{-2} \mathrm{~s}^{-1}$ respectively). This result is consistent with previous findings, ${ }^{9}$ which also observed a microniche with a similar flux pattern for $\mathrm{Fe}$ and Mn. Microniches principally form because of microbial driven mobilization/depletion of metals, often catalyzed by the hotspot having different rates of organic carbon decomposition/mineralization and/or different microbial communities, compared with the surrounding soils.$^{45}$ Products of microbial metabolism and synthesis, especially, can contribute to metal mobility. ${ }^{46}$ For example, Fe flux maxima may be caused by Fe reducing bacteria mediated reductive dissolution. The organic matter from root exudates can also serve as an electron donor for Fe reduction. It promotes the dissimilatory reduction of adsorbed $\mathrm{As}(\mathrm{V})$ by dissimilatory arsenatereducing bacteria and releases As into the aqueous phase. ${ }^{47}$ 
Based on Pearson correlation analysis there are significantly positive correlations between As and Fe fluxes on SPR-IDA DGT across the root tip zones $(p<0.01$, Figure $\mathrm{S} 4)$, indicating a close association between the two elements. Although $\mathrm{Pb}$ also exhibits a strong positive relationship with As and Fe, two different correlation patterns emerge.

One associates with the center of the flux feature, the other a surrounding/bordering zone in close proximity to the periphery of the maxima and $\mathbf{O}+\mathbf{R}$ zone. Interestingly, there is also a stronger association between the supply of $\mathrm{Pb}$ and $\mathrm{Mn}$ in this edge region. Manganese hydroxides are superior scavengers of $\mathrm{Pb}$ compared with other metal hydroxides, and are about $\sim 40$ times more effective as an adsorbent of $\mathrm{Pb}$ than $\mathrm{FeOH},{ }^{48}$ but a general lack of co-localized release of $\mathrm{Mn}$ and $\mathrm{Pb}$ in this studied plant-soil system suggests this is not a dominant reaction state. Metal-oxide ternary complexes can also influence bioavailability, especially in carbon rich environments, and determine if metal adsorption at oxide surfaces is enhanced or inhibited by the presence of ligands. ${ }^{48}$ In the dynamic environments of root apices and flux maxima the spatial variability we document reveals the potential for a wide range of metal/ligand ratios to exist even within a confined area.

The Flux Comparison between Different DGT Gels. Consistent with the SPRIDA-gel ion maps, both the PZ and PF-based DGT's (Figure $3 \& 4$ ) also revealed a cooccurrence of As and Fe flux maxima, and that this was associated with upper/shallower root apice zones of the rhizosphere. For PZ gel (Figure 3), enhanced metal fluxes were evident along the aerobic-anaerobic interface, but the flux maxima in the tip zone remained the strongest/most intense region of As and Fe supply. Concentrations of 
labile As inside the $\mathbf{O}+\mathbf{R}$ were consistently low, ranging between $1-1.4 \mathrm{pg} \cdot \mathrm{cm}^{3} \cdot \mathrm{s}^{-1}$. The same trends were detected by PF gels (Figure 4). Fluxes of As were strongest within the rhizosphere of the root tip, not where $\mathrm{O}_{2}$ intensity was greatest but in a transition zone of relatively unstable aeration. This is consistent with the solute images captured by the SPR-IDA DGT and previous studies. ${ }^{9,49}$

In contrast to As and Fe, a relatively low flux of $\mathrm{P}$ occurred within the $\mathbf{O}+\mathbf{R}$ (Figure $3 \& 4$ ), which might be ascribed, in part, to its rapid depletion by root uptake, ${ }^{50}$ and/or fixation by Fe plaque. ${ }^{51}$ The fluxes of P at RTA are 54\% lower than the bulk/field soil area as measured by the PF DGT, and 79\% less based on PZ DGT detection. Absorption of $\mathrm{P}$, in most plants, is constrained by kinetics, but under conditions of unhindered diffusion from $\mathbf{O}-\mathbf{B} / \mathrm{bulk} /$ field soils to the root-soil interface uptake is rapid. ${ }^{52}$ However, the patterns of low P mobilization/depletion do not follow the root system directly. Instead they map more closely to the edges of the $\mathbf{O}+\mathbf{R}$, suggesting the importance of redox rather than root exudates as an overarching/primary control on $\mathrm{P}$ availability. The role of redox conditions as a determinant of $\mathrm{P}$ availability is further evidenced by DGT being a poor indicator of $\mathrm{P}$ availability in rice, when the redox potentials of tested soils are not representative of field conditions. ${ }^{53}$ Oxidation is a major contributor to acidification within the rooting zone and rhizosphere acidification plays a key role in $\mathrm{P}$ acquisition by rice ${ }^{50}$ Furthermore, $\mathrm{P}$ also modulates the behaviors of the other elements, such as $\mathrm{Pb}$, with $\mathrm{Pb}$-phosphate being one of the most insoluble forms of $\mathrm{Pb}$ in soil. ${ }^{48}$ While, P can also promote As release by competing for binding sites on Fe-hydroxide surfaces, with Fe plaque formation around roots found to increase $\mathrm{P}$ uptake. ${ }^{54}$ It is 
therefore, surprising that the As and Fe root tip maximum, corresponded to a significant minima in $\mathrm{P}$ release (Figure 3), which was accompanied by a series of significant/negative correlations of As or Fe with P fluxes (Table S4) across the root tip zones.

Solid-Water Partitioning Contributes to Metals Mobility. The results from DGT sampling provide a direct measurement of the mean in situ flux from the solid phase to porewater. ${ }^{55}$ The subsoils collected specifically from soil regions with different $\mathrm{O}_{2}$ concentrations showed no significant difference in their solid phase concentrations for $\mathrm{As}, \mathrm{Pb}$, and $\mathrm{Fe}$. However, porewater showed significant variation in $\mathrm{As}, \mathrm{Fe}$, and $\mathrm{Mn}$ between $\mathbf{O}-\mathbf{B}$ areas and the $\mathbf{O}+\mathbf{R}$ zones $(p<0.05)$ (Figure 5). Supporting the DGT observations, the $\mathbf{O}+\mathbf{R}$ zone had lower porewater concentrations. Although there was some enrichment of $\mathrm{Mn}$ in the $\mathbf{O}+\mathbf{R}$, the soil-water partitioning $(\mathrm{Kd})$ value was higher than O-B regions, which is similar to the trends for As and Fe, i.e. lower element solubility. Redox gradients explain the metal partitioning between these two distinct areas. Some care is needed when interpreting these Kd values though, as calculation of partition coefficients assume equilibrium between porewater and solid phase concentration. In the presence of a growing root a true equilibrium state might not be achieved fully. However, the volume of samples collected was sufficient to ensure that porewaters were not just targeting zones directly at the soil-root interface.

At this stage in plant development there were minimal impacts on general soil enrichment patterns, but significant alterations in element mobility behaviors. The oxic conditions promote metal precipitation, and with the formation of $\mathrm{Fe}$ and $\mathrm{Mn}$ 
oxyhydroxides in $\mathbf{O}+\mathbf{R}$ zones, the increased availability of binding sites, causes a corresponding decrease in the concentration of dissolved TE's in the affected soils. Furthermore $\mathrm{As}, \mathrm{Fe}$, and $\mathrm{Mn}$ are more mobile in their reduced state, migrating strongly in response to naturally occurring gradients in solute concentration towards oxidized soil. ${ }^{56}$ It is these processes from which significant changes in total element profiles within the underground topsoil evolve. However, our findings of a flux maxima and a decoupling of metal and $\mathrm{P}$ behaviors across the tip regions of rice roots indicates a different chemical process, distinct to the situation occurring within the general oxygen influenced rhizosphere, is dominant. This Fe flux maxima and its superimposition on the outer boundary of the aerobic zone is suggestive of an overriding abiotic process. It also agrees with the hypothesis that the flux arises from oxidation-mediated $\mathrm{pH}$ changes on $\mathrm{Fe}(\mathrm{II})$ mobility. ${ }^{9}$

Environmental Implications. Understanding that the rhizosphere environment greatly alters element mobilization in discrete/small localized patches is a step forward in developing strategies for minimizing plant uptake and grain contamination. The solute chemistries of the emergent rice rhizosphere vary from that of the surrounding bulk/field soils, and we show that within these zones considerable chemical heterogeneity also exists. Indeed, much of our understanding of the elemental cycling within paddy fields, at least from the perspective of nutrient management/fertilizer applications/soil conditioners follows the concept of homogenous, reciprocal interaction, employing a chemistry where the reaction kinetics of ions/molecules are in a well-mixed environment. The spatial structure of the rice rhizosphere used to be 
ignored in the overall system dynamics. Indeed, the ploughed paddy topsoil does begin the cropping cycle relatively homogenized, but after flooding and overtime (0-4 months) the spatial diversity of the system increases greatly. ${ }^{33}$ These initial first steps in solute interchange and soil surface interactions created by the emergent rhizospheres of the newly planted rice, are important because they create zones of localized enrichment/depletion in elemental bioavailability, forming different ecological niches (Figure 1), thus impacting plant uptake through diffusion and resupply. However, these gradients in porewater elements availability, later develop/establish into chemically stratified zones differing with more permanency in their solid phase composition and stoichiometry, such as is the case with Fe or Mn plaque aggregation.

In this work we capture for the first time, solute maps for $\mathrm{As}, \mathrm{Fe}, \mathrm{Pb}, \mathrm{Mn}, \mathrm{O}_{2}$ and $\mathrm{P}$, in a series of newly formed rhizospheres. We were able to validate previous observations $^{9}$ of an As and Fe flux maxima located around root apice zones at the interface between oxic-anoxic conditions, at larger spatial scales, using a variety of DGT-optode multilayer configurations, a different rice cultivar, and using a paddy soil naturally enriched in As. Moreover, we demonstrate that the flux phenomenon is common and forms predominantly around the tip regions of the upper root zone. $\mathrm{P}$ chemistries in the FM flux zone were also captured along with As, revealing a surprising disconnect between $\mathrm{As}$ or $\mathrm{Fe}$ mobilization and $\mathrm{P}$ release. Element distributions in porewater and subsoils demonstrate the diffusion gradient is one of the explanations for their mobilization. Further, this whole-rhizosphere demonstration of solute behaviors provides a new perspective on the development of spatial structure 
within rice rhizospheres, a framework that can be used to further understand localized patterns of element uptake and environment sensing by plant roots, microbial diversity/function and critically important to As especially, speciation transformations and cycling.

\section{ASSOCIATED CONTENT}

Experimental: Optode Sensor Fabrication and $\mathrm{O}_{2}$ imaging in Rice Rhizosphere. Root development assessment. QA/QC. Solid-Water Distribution Coefficient (Kd). Sulfur and metals concentration in the soil by ED-XRF (Table S1); Masses of analytes for ICP-MS (PerkinElmer NexION 300X) analysis to characterize laboratory DGT performance (Table S2); Certified and measured concentrations of elements in GBW07405 soil reference material for trace metals analysis using ED-XRF (Table S3); Pearson correlation coefficient matrix of various element fluxes around the root tip on PZ gel (Table S4); The results of PCA analysis corresponding with figure 1, 2/S3, and 3/S4 (Table S5); The distribution coefficients (Kd) of elements in different regions (Table S6); The photography of root in rhizotrons (Figrue $\mathrm{S} 1$ ); Visualization of $\mathrm{O}_{2}$, As, and other elements around roots corresponding with figure 1 (Figure S2); Chemical images of $\mathrm{O}_{2}$ and elements distribution around single rice root with SPR-IDA DGT corresponding with figure 2 (Figure S3); Pearson scatterplots for different elements around root tips corresponding with SPR-IDA gel in figure 1 (Figure S4). Twodimensional visualization of As and other elements by ZrO DGT corresponding with figure 3 (Figure S5); The physic-chemical characteristics in rice rhizosphere during 
460 the growth stage (Figure S6).

461

462

\section{AUTHOR INFORMATION}

\section{Corresponding Authors}

464

*Phone: +44-0-28-9097-6539; e-mail: p.williams@qub.ac.uk (P.N.W.).

*Phone: 0086-25-89680632; e-mail: esluojun@nju.edu.cn (J.L.).

\section{ORCID}

467

468

469

470

471

472

473

474

475

476

477

478

479

480

481

482

Paul N. Williams: 0000-0002-0723-7997

Lena Q. Ma: 0000-0002-8463-9957

Jun Luo: 0000-0002-3480-8900

Notes

The authors declare no competing financial interest.

\section{ACKNOWLEDGMENTS}

This work was funded by the National Natural Science Foundation of China (No. 41771271), the Fundamental Research Funds for the Central Universities (021114380126), National Natural Science Foundation of China (No. 41807023), and Jiangsu Province Natural Science Foundation (BK20180344). The study also received support from the Newton Fund/Royal Society and NFSC (R1504GFS and 21511130063).

\section{REFERENCES}

(1) Carey, M.; Meharg, C.; Williams, P.; Marwa, E.; Jiujin, X.; Farias, J. G.; De Silva, P. M. C.; SignesPastor, A.; Lu, Y.; Nicoloso, F. T., Global Sourcing of Low-Inorganic Arsenic Rice Grain. Expos. Health 
2019, 1-9.

(2) Meharg, A. A.; Williams, P. N.; Adomako, E.; Lawgali, Y. Y.; Deacon, C.; Villada, A.; Cambell, R. C.; Sun, G.; Zhu, Y.-G.; Feldmann, J., Geographical variation in total and inorganic arsenic content of polished (white) rice. Environ. Sci. Technol. 2009, 43, (5), 1612-1617.

(3) Williams, P.; Price, A.; Raab, A.; Hossain, S.; Feldmann, J.; Meharg, A. A., Variation in arsenic speciation and concentration in paddy rice related to dietary exposure. Environ. Sci. Technol. 2005, 39, (15), 5531-5540.

(4) Savage, L.; Carey, M.; Hossain, M.; Islam, M. R.; de Silva, P.; Williams, P. N.; Meharg, A. A., Elevated Trimethylarsine Oxide and Inorganic Arsenic in Northern Hemisphere Summer Monsoonal Wet Deposition. Environ. Sci. Technol. 2017, 51, (21), 12210-12218.

(5) Muehe, E. M.; Wang, T.; Kerl, C. F.; Planer-Friedrich, B.; Fendorf, S., Rice production threatened by coupled stresses of climate and soil arsenic. Nat. Commun. 2019, 10, (1), 4985.

(6) Meharg, A. A.; Hartley-Whitaker, J., Arsenic uptake and metabolism in arsenic resistant and nonresistant plant species. New Phytol. 2002, 154, (1), 29-43.

(7) Wang, P.; Zhang, W.; Mao, C.; Xu, G.; Zhao, F.-J., The role of OsPT8 in arsenate uptake and varietal difference in arsenate tolerance in rice. J. Exp. Bot. 2016, 67, (21), 6051-6059.

(8) Ma, J. F.; Yamaji, N.; Mitani, N.; Xu, X.-Y.; Su, Y.-H.; McGrath, S. P.; Zhao, F.-J., Transporters of arsenite in rice and their role in arsenic accumulation in rice grain. Proc. Natl. Acad. Sci. 2008, 105, (29), 9931-9935.

(9) Williams, P. N.; Santner, J.; Larsen, M.; Lehto, N. J.; Oburger, E.; Wenzel, W.; Glud, R. N.; Davison, W.; Zhang, H., Localized flux maxima of arsenic, lead, and iron around root apices in flooded lowland rice. Environ. Sci. Technol. 2014, 48, (15), 8498-8506.

(10) Duker, A. A.; Carranza, E.; Hale, M., Arsenic geochemistry and health. Environ. Int. 2005, 31, (5), 631-641.

(11) Seyfferth, A. L.; Webb, S. M.; Andrews, J. C.; Fendorf, S., Arsenic localization, speciation, and cooccurrence with iron on rice (Oryza sativa L.) roots having variable Fe coatings. Environ. Sci. Technol. 2010, 44, (21), 8108-8113.

(12) Yamaguchi, N.; Ohkura, T.; Hikono, A.; Yamaguchi, H.; Hashimoto, Y.; Makino, T., Effects of Iron Amendments on the Speciation of Arsenic in the Rice Rhizosphere after Drainage. Soils 2017, 1 , (1), 6.

(13) Li, B.; Zhou, S.; Wei, D.; Long, J.; Peng, L.; Tie, B.; Williams, P. N.; Lei, M., Mitigating arsenic accumulation in rice (Oryza sativa L.) from typical arsenic contaminated paddy soil of southern China 
using nanostructured $\alpha-\mathrm{MnO}_{2}$ : Pot experiment and field application. Sci. Total Environ. 2019, 650, 546556.

(14) Xu, X.; Chen, C.; Wang, P.; Kretzschmar, R.; Zhao, F.-J., Control of arsenic mobilization in paddy soils by manganese and iron oxides. Environ. Pollut. 2017, 231, 37-47.

(15) Violante, A.; Caporale, A. G., Biogeochemical processes at soil-root interface. Journal of Soil Science \& Plant Nutrition 2015, 15, (2), 7.

(16) Jacob, D. L.; Otte, M. L., Long-term effects of submergence and wetland vegetation on metals in a 90-year old abandoned $\mathrm{Pb}-\mathrm{Zn}$ mine tailings pond. Environ. Pollut. 2004, 130, (3), 337-345.

(17) Lee, Y. J.; Mynampati, K.; Drautz, D.; Arumugam, K.; Williams, R.; Schuster, S.; Kjelleberg, S.; Swarup, S. In Understanding Aquatic Rhizosphere Processes Through Metabolomics and Metagenomics Approach, EGU General Assembly Conference Abstracts, 2013; 2013.

(18) Mei, X. Q.; Wong, M. H.; Yang, Y.; Dong, H. Y.; Qiu, R. L.; Ye, Z. H., The effects of radial oxygen loss on arsenic tolerance and uptake in rice and on its rhizosphere. Environ. Pollut. 2012, 165, 109-17.

(19) Wang, M. Y.; Chen, A. K.; Wong, M. H.; Qiu, R. L.; Cheng, H.; Ye, Z. H., Cadmium accumulation in and tolerance of rice (Oryza sativa L.) varieties with different rates of radial oxygen loss. Environ. Pollut. 2011, 159, (6), 1730-6.

(20) Kuzyakov, Y.; Blagodatskaya, E., Microbial hotspots and hot moments in soil: concept \& review. Soil Biol. Biochem. 2015, 83, 184-199.

(21) Chen, Z.; Zhu, Y. G.; Liu, W. J.; Meharg, A. A., Direct evidence showing the effect of root surface iron plaque on arsenite and arsenate uptake into rice (Oryza sativa) roots. New Phytol. 2005, 165, (1), 91-97.

(22) Jia, Y.; Huang, H.; Chen, Z.; Zhu, Y.-G., Arsenic uptake by rice is influenced by microbe-mediated arsenic redox changes in the rhizosphere. Environ. Sci. Technol. 2014, 48, (2), 1001-1007.

(23) Hinsinger, P.; Bengough, A. G.; Vetterlein, D.; Young, I. M., Rhizosphere: biophysics, biogeochemistry and ecological relevance. Plant Soil 2009, 321, (1-2), 117-152.

(24) Koren, K.; Brodersen, K. E.; Jakobsen, S. L.; Kühl, M., Optical sensor nanoparticles in artificial sediments-a new tool to visualize $\mathrm{O}_{2}$ dynamics around the rhizome and roots of seagrasses. Environ. Sci. Technol. 2015, 49, (4), 2286-2292.

(25) Larsen, M.; Santner, J.; Oburger, E.; Wenzel, W. W.; Glud, R. N., O 2 dynamics in the rhizosphere of young rice plants (Oryza sativa L.) as studied by planar optodes. Plant Soil 2015, 390, (1-2), 279-292.

(26) Hinsinger, P.; Gobran, G. R.; Gregory, P. J.; Wenzel, W. W., Rhizosphere geometry and 
heterogeneity arising from root-mediated physical and chemical processes. New Phytol. 2005, 168, (2), 293-303.

(27) Davison, W.; Zhang, H., In situ speciation measurements of trace components in natural waters using thin-film gels. Nature 1994, 367, (6463), 546.

(28) Zhang, H.; Zhao, F.-J.; Sun, B.; Davison, W.; Mcgrath, S. P., A new method to measure effective soil solution concentration predicts copper availability to plants. Environ. Sci. Technol. 2001, 35, (12), 2602-2607.

(29) Stahl, H.; Warnken, K. W.; Sochaczewski, L.; Glud, R. N.; Davison, W.; Zhang, H., A combined sensor for simultaneous high resolution 2-D imaging of oxygen and trace metals fluxes. Limnology and Oceanography: Methods 2012, 10, (5), 389-401.

(30) Han, C.; Ren, J.; Wang, Z.; Yang, S.; Ke, F.; Xu, D.; Xie, X., Characterization of phosphorus availability in response to radial oxygen losses in the rhizosphere of Vallisneria spiralis. Chemosphere 2018, 208, 740-748.

(31) Kreuzeder, A.; Santner, J.; Prohaska, T.; Wenzel, W. W., Gel for simultaneous chemical imaging of anionic and cationic solutes using diffusive gradients in thin films. Anal. Chem. 2013, 85, (24), 1202812036 .

(32) Davison, W.; Fones, G. R.; Grime, G. W., Dissolved metals in surface sediment and a microbial mat at $100-\mu \mathrm{m}$ resolution. Nature $1997,387,(6636), 885$.

(33) Fang, W.; Williams, P. N.; Fang, X.; Amoah-Antwi, C.; Yin, D.; Li, G.; Ma, L. Q.; Luo, J., FieldScale Heterogeneity and Geochemical Regulation of Arsenic, Iron, Lead, and Sulfur Bioavailability in Paddy Soil. Environ. Sci. Technol. 2018, 52, (21), 12098-12107.

(34) Das, H.; Sengupta, P.; Hossain, A.; Islam, M.; Islam, F., Diversity of environmental arsenic pollution in Bangladesh. Bangladesh environment 2002, 1, 234-244.

(35) Warnken, K. W.; Zhang, H.; Davison, W., Performance characteristics of suspended particulate reagent-iminodiacetate as a binding agent for diffusive gradients in thin films. Anal. Chim. Acta. 2004, $508,(1), 41-51$.

(36) Luo, J.; Zhang, H.; Santner, J.; Davison, W., Performance characteristics of diffusive gradients in thin films equipped with a binding gel layer containing precipitated ferrihydrite for measuring arsenic (V), selenium (VI), vanadium (V), and antimony (V). Anal. Chem. 2010, 82, (21), 8903-8909.

(37) Guan, D.-X.; Williams, P. N.; Luo, J.; Zheng, J.-L.; Xu, H.-C.; Cai, C.; Ma, L. Q., Novel precipitated zirconia-based DGT technique for high-resolution imaging of oxyanions in waters and sediments. Environ. Sci. Technol. 2015, 49, (6), 3653-3661. 
(38) Lehto, N. J.; Davison, W.; Zhang, H., The use of ultra-thin diffusive gradients in thin-films (DGT) devices for the analysis of trace metal dynamics in soils and sediments: a measurement and modelling approach. Environ. Chem. 2012, 9, (4), 415-423.

(39) Puy, J.; Galceran, J.; Cruz-González, S.; David, C. A.; Uribe, R.; Lin, C.; Zhang, H.; Davison, W., Measurement of metals using DGT: impact of ionic strength and kinetics of dissociation of complexes in the resin domain. Anal. Chem. 2014, 86, (15), 7740-7748.

(40) Larsen, M.; Borisov, S. M.; Grunwald, B.; Klimant, I.; Glud, R. N., A simple and inexpensive high resolution color ratiometric planar optode imaging approach: application to oxygen and $\mathrm{pH}$ sensing. Limnology and Oceanography: Methods 2011, 9, (9), 348-360.

(41) Kirk, G., The Biogeochemistry of Submerged Soils. 2004.

(42) Duckworth, O. W.; Sposito, G., Siderophore-promoted dissolution of synthetic and biogenic layertype Mn oxides. Chemical Geology 2007, 242, (3-4), 497-508.

(43) Madison, A. S.; Tebo, B. M.; Mucci, A.; Sundby, B.; Luther, G. W., Abundant porewater Mn (III) is a major component of the sedimentary redox system. Science 2013, 341, (6148), 875-878.

(44) Davison, W., Iron and manganese in lakes. Earth-Sci. Rev 1993, 34, (2), 119-163.

(45) Fones, G. R.; Davison, W.; Hamilton-Taylor, J., The fine-scale remobilization of metals in the surface sediment of the North-East Atlantic. Cont. Shelf Res. 2004, 24, (13-14), 1485-1504.

(46) Unz, R. F.; Shuttleworth, K. L., Microbial mobilization and immobilization of heavy metals. Curr. Opin. Biotech. 1996, 7, (3), 307-310.

(47) Oremland, R. S.; Stolz, J. F., The ecology of arsenic. Science 2003, 300, (5621), 939-944.

(48) Hettiarachchi, G. M.; Pierzynski, G. M.; Ransom, M. D., In situ stabilization of soil lead using phosphorus and manganese oxide. Environ. Sci. Technol. 2000, 34, (21), 4614-4619.

(49) Marschner, H.; Rimmington, G., Mineral nutrition of higher plants. Plant, cell \& environment 1988, $11,(2), 147-148$.

(50) Hinsinger, P., Bioavailability of soil inorganic P in the rhizosphere as affected by root-induced chemical changes: a review. Plant Soil 2001, 237, (2), 173-195.

(51) Xing, X.; Ding, S.; Liu, L.; Chen, M.; Yan, W.; Zhao, L.; Zhang, C., Direct evidence for the enhanced acquisition of phosphorus in the rhizosphere of aquatic plants: a case study on Vallisneria natans. Sci. Total Environ. 2018, 616, 386-396.

(52) Johri, A. K.; Oelmüller, R.; Dua, M.; Yadav, V.; Kumar, M.; Tuteja, N.; Varma, A.; Bonfante, P.; 
659

660

661

662

663

664

665

666

667

668

669

670

671

672

673

674

675

676

677

678

679

680

681
Persson, B. L.; Stroud, R. M., Fungal association and utilization of phosphate by plants: success, limitations, and future prospects. Frontiers in microbiology 2015, 6, 984.

(53) Six, L.; Smolders, E.; Merckx, R., The performance of DGT versus conventional soil phosphorus tests in tropical soils - maize and rice responses to P application. Plant Soil 2013, 366, (1-2), 49-66.

(54) Xu, D.; Xu, J.; He, Y.; Huang, P., Effect of iron plaque formation on phosphorus accumulation and availability in the rhizosphere of wetland plants. Water, air, and soil pollution 2009, 200, (1-4), 79-87.

(55) Lehto, N. J.; Davison, W.; Zhang, H.; Tych, W., Analysis of micro-nutrient behaviour in the rhizosphere using a DGT parameterised dynamic plant uptake model. Plant Soil 2006, 282, (1-2), 227 238.

(56) Begg, C.; Kirk, G.; Mackenzie, A.; Neue, H. U., Root-induced iron oxidation and pH changes in the lowland rice rhizosphere. New Phytol. 1994, 128, (3), 469-477. 
682

683 Table 1. Chemical and Spatial Characteristics. Area $\left(\mathrm{cm}^{2}\right)$ and Flux $\left(\mathrm{pg} \mathrm{cm} \mathrm{cm}^{-2} \mathrm{~s}^{-1}\right)$ 684 measurements for rhizosphere deployed SPR-IDA DGT (Figure 1).

\begin{tabular}{cccccc}
\hline & Area & As & $\mathrm{Fe}$ & $\mathrm{Pb}$ & $\mathrm{Mn}$ \\
\hline $\begin{array}{c}\text { Flux Maxima } \\
\text { (Root apex rhizosphere zones) }\end{array}$ & 0.46 & $0.049 \pm 0.029$ & $16.74 \pm 8.507$ & $0.081 \pm 0.029$ & $5.736 \pm 0.72$ \\
$\begin{array}{c}\text { Aerobic Rhizosphere } \\
\begin{array}{c}\text { Non-rhizosphere/anaerobic } \\
\text { soil }\end{array}\end{array}$ & 6.58 & $0.008 \pm 0.001$ & $2.806 \pm 0.959$ & $0.09 \pm 0.006$ & $4.848 \pm 0.936$ \\
\hline
\end{tabular}

685

Zonal element fluxes are presented as means \pm standard deviation. Regions of interest included a

686 flux maxima associated with root apex rhizosphere zones (FM), aerobic rhizosphere $(\mathrm{O}+\mathrm{R})$, and

687 non-rhizosphere/anaerobic soil (O-B). The size of the three zones are $0.46,6.58$, and $21.5 \mathrm{~cm}^{2}$,

688 containing 54,770 , and 2520 points, respectively, i.e. the deviations are derived from 54,770 , and

689 2520 replicates.

690 
(a) $\mathrm{O}_{2}$

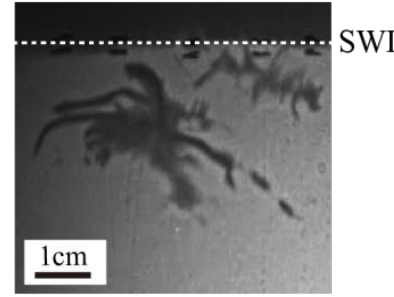

(d) $\mathrm{Fe}$

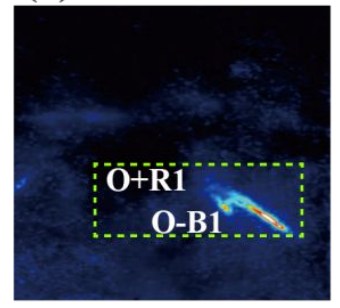

(e) $\mathrm{Mn}$

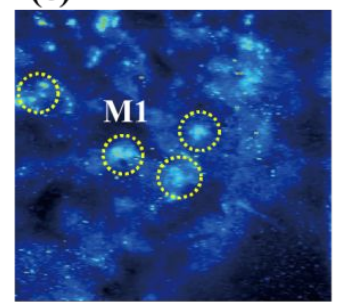

(b) $3 \mathrm{D} \mathrm{O}_{2}$

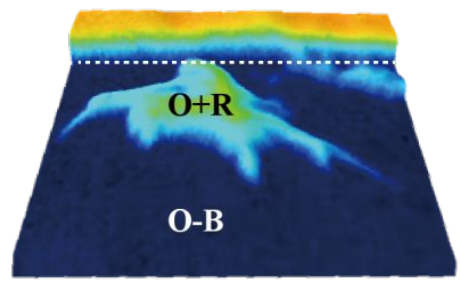

(f) PCA plots

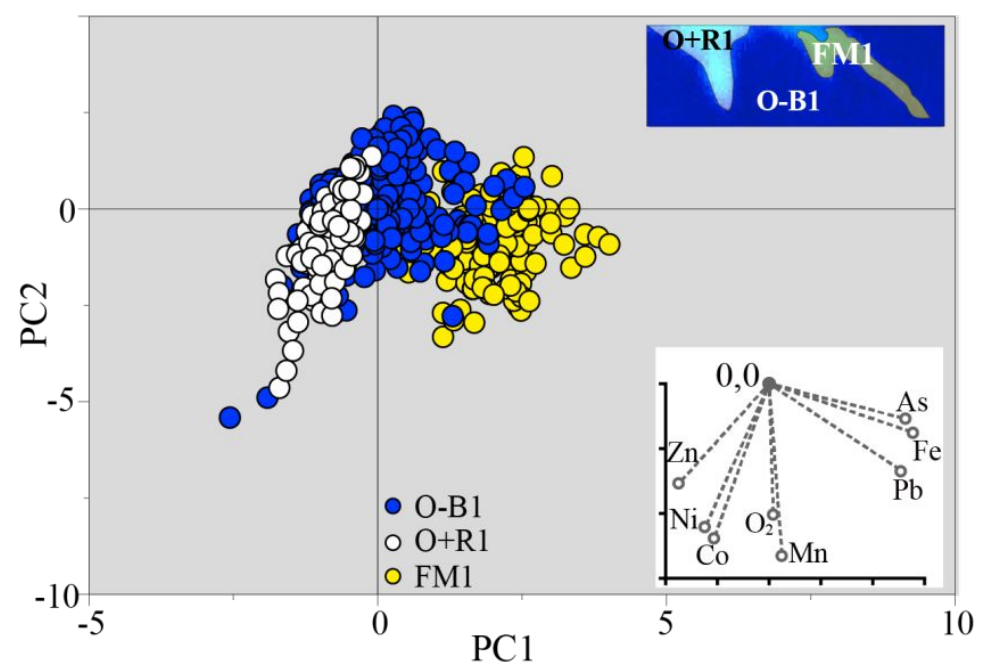

(c) $3 \mathrm{D} \mathrm{As}$

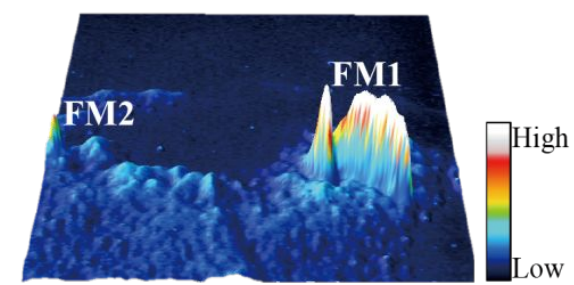

PC1

Figure 1. Solute fluxes around a set of four-week-old rice roots with SPR-IDA DGT and $\mathrm{O}_{2}$ planar optodes. (a) image of $\mathrm{O}_{2}$ distribution obtained before the deployment of the multilayer DGT/optode system. The horizontal dashed lines show the soil-water interface (SWI). (b) $3 \mathrm{D}$ plot of $\mathrm{O}_{2}$ distribution in the rice rhizosphere, $\mathrm{O}+\mathrm{R}$ denotes the aerobic rhizosphere, $\mathrm{O}-\mathrm{B}$ denotes the anaerobic bulk soil. (c) 3D plot of As fluxes in rice rhizosphere. All 2D elemental plots are shown in figure S2. FM denotes the flux maxima associated with rhizosphere soil in root apex zones. (d) Fe. The green/dash-lined box shows the corresponding data extraction region/transect used for PCA analysis. (e) Mn. The yellow circles indicate flux microniches (labelled as M1) (f) PCA plot of elements in different regions, aerobic rhizosphere $(\mathrm{O}+\mathrm{R} 1)$, nonrhizosphere/anaerobic soil (O-B1), flux maxima in a root apex rhizosphere zone (FM1) (the original data are shown in table S5). For all images, the metal fluxes $\left(f_{\mathrm{DGT}}, \mathrm{pg} \mathrm{\textrm {cm } ^ { - 2 }}\right.$ $\mathrm{s}^{-1}$ ) and oxygen concentration (percent air saturation) increased sequentially with the color scale shown from blue to white. The scales in the figure represent the following ranges from $0 \%$ to $100 \%$ for $\mathrm{O}_{2}$, from $0.004-0.126$ for As, from $0-42.144$ for $\mathrm{Fe}$, and from 0.71 to 22.39 for $\mathrm{Mn}$. 
(a) root photograph

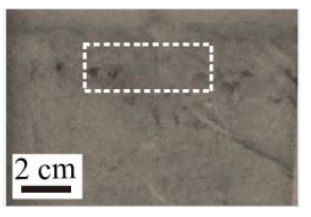

(b) $3 \mathrm{D} \mathrm{O}_{2}$

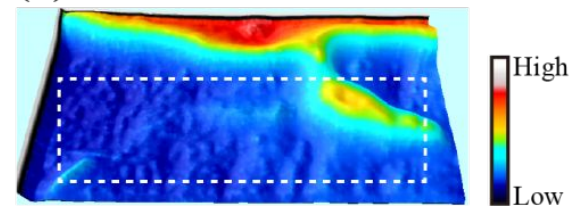

(c) $\mathrm{O}_{2}$

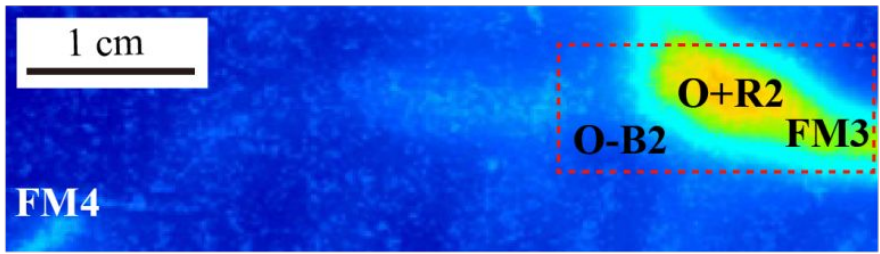

(d) As

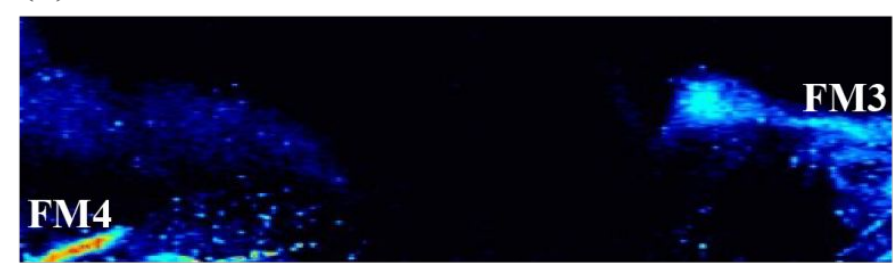

(e) $\mathrm{Fe}$

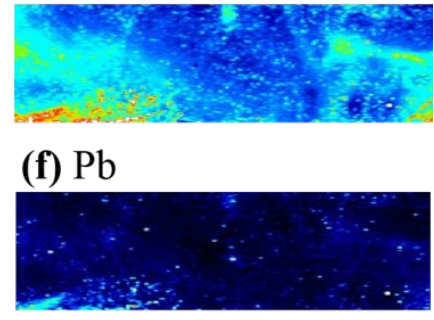

(g) $\mathrm{Mn}$

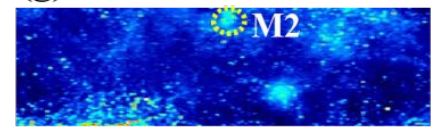

(h) $\mathrm{Co}$

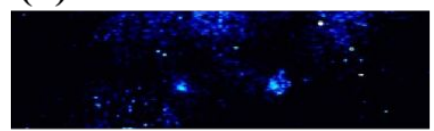

(i) $\mathrm{Ni}$

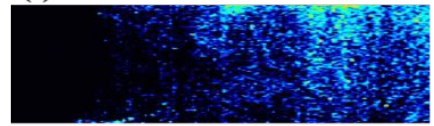

(j) $\mathrm{Zn}$

Figure 2. Root and microniche induced solute fluxes, confirmatory experiment using SPR-IDA DGT and $\mathrm{O}_{2}$ planar optodes. Measurements were made by deploying an SPR IDA-DGT $/ \mathrm{O}_{2}$ multilayer system within a rice rhizosphere. (a) Photographic image of the soil area and the root zone subjected to chemical imaging. The white dash box shows the imaging region for $\mathrm{O}_{2}$. (b) $3 \mathrm{D}$ plot of $\mathrm{O}_{2}$ distribution in the rhizosphere. The white dash box shows the imaging region for elements. (c) $2 \mathrm{D}$ plot of $\mathrm{O}_{2}$ concentration in the rhizosphere corresponding with DGT element imaging. The red/dash-lined box shows the corresponding regions for the companion PCA plot (figure S3). $\mathrm{O}+\mathrm{R} 2$ denotes the aerobic rhizosphere, O-B2 denotes nonrhizosphere/anaerobic bulk soil, FM3 denotes the flux maxima associated with the root apice rhizosphere. (d) As, FM3 indicates flux maxima around root apices. (e) Fe. (f) $\mathrm{Pb}$. (g) Mn, the yellow dashed circle indicates a flux microniche (label as M2). (h) Co. (i) Ni. (j) Zn. The metal fluxes $\left(f_{\text {DGT }}, \mathrm{pg} \mathrm{cm}^{-2} \mathrm{~s}^{-1}\right)$ and oxygen concentration (percent air saturation) increased sequentially with the color scale shown from blue to white. The scales in the figure represent the following ranges from $0 \%$ to $100 \%$ for $\mathrm{O}_{2}$, from $0.518-16.378$ for $\mathrm{Fe}$, from 0.016 to 0.046 for $\mathrm{As}$, from $0-0.09$ for $\mathrm{Pb}$, from 0.1120.723 for $\mathrm{Mn}$, from 0.026-0.449 for $\mathrm{Co}$, from 0.028-0.146 for $\mathrm{Zn}$, from 0.051-0.115 for Ni. 
(a) $\mathrm{O}_{2}$

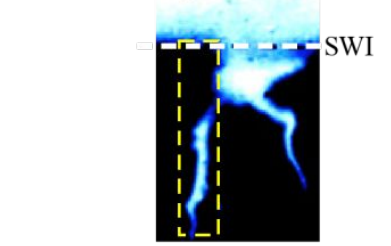

(b) $\mathrm{P}$

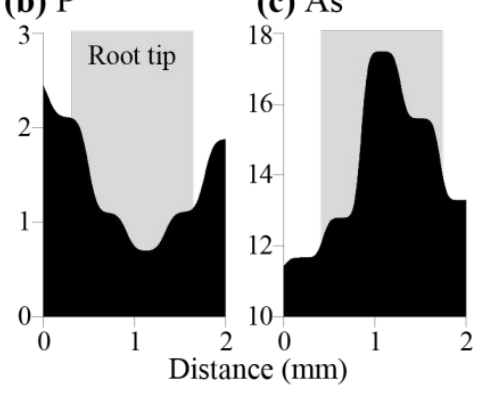

(d) $\mathrm{O}_{2}$

(e) As

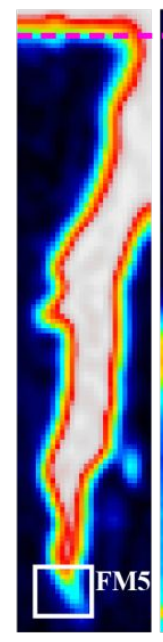

(f) $\mathrm{Fe}$

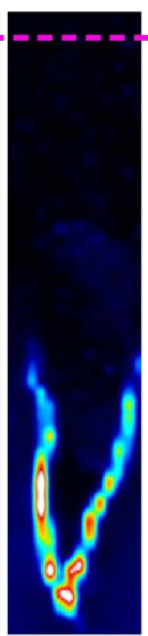

(g) $\mathrm{P}$

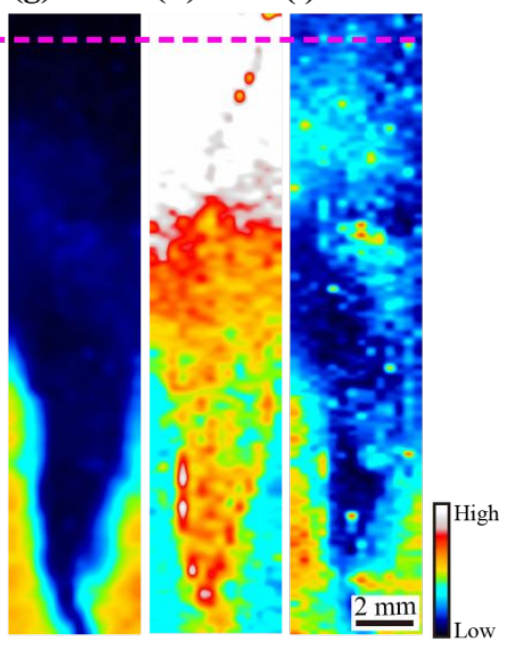

Figure 3. Chemical images of $\mathrm{O}_{2}$ and element distribution with ZrO DGT. Element fluxes are obtained by deploying ultrathin precipitated $\mathrm{ZrO}$ gel in the rhizosphere for $12 \mathrm{~h}$. (a) $2 \mathrm{D} \mathrm{O}_{2}$ distribution in the whole rhizosphere. The horizontal dashed lines show the soil-water interface (SWI). The yellow box denotes the imaging region of elements. (b) P flux transect (black shading). The grey shading indicates the root apex associated rhizosphere. (c) As flux transect (black shading). The grey shading indicates the root apex associated rhizosphere. (d) $\mathrm{O}_{2}$ concentration around the root. The white box denotes the data extraction regions featured in the P/As biplots. (e) As (f) Fe (g) P (h) Mo (i) W. The metal/element fluxes $\left(f_{\text {DGT }}, \mathrm{pg} \mathrm{cm}^{-2} \mathrm{~s}^{-1}\right)$ and oxygen concentration (percent air saturation) increased sequentially with the color scale shown from blue to white. The scales in the figure represent the following ranges from $0 \%$ to $100 \%$ for $\mathrm{O}_{2}$, from 0.09 to 17.9 for As, from 0.42-10.27 for $\mathrm{Fe}$, from 0.02-2.55 for $\mathrm{P}$, from 0.17-5.62 for Mo, and from 1.24-5.87 for W. Although Mo and W images are not discussed in the text, they were included to verify/support the distinction in chemical behavior between the root apex rhizosphere zone and the bulk soil environment. 
(a) $\mathrm{O}_{2}$ distribution

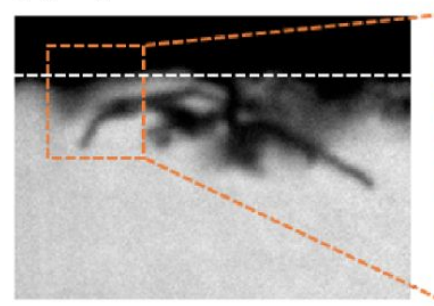

(e) As flux transect

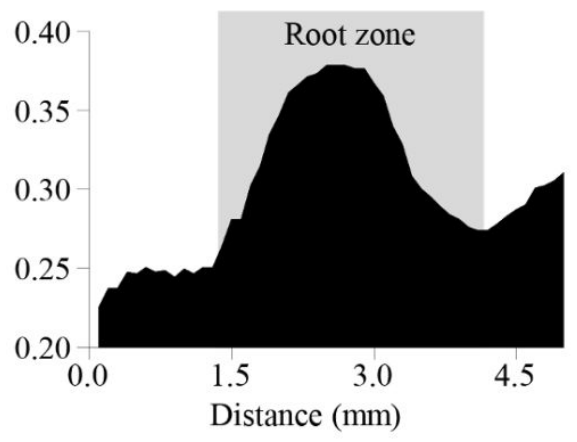

(c) As

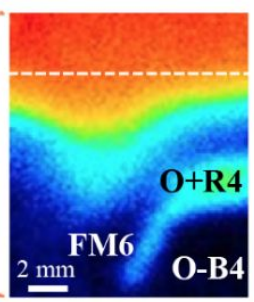

(d) $\mathrm{P}$
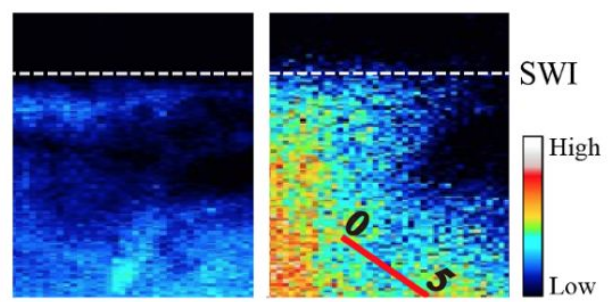

(f) P flux transect

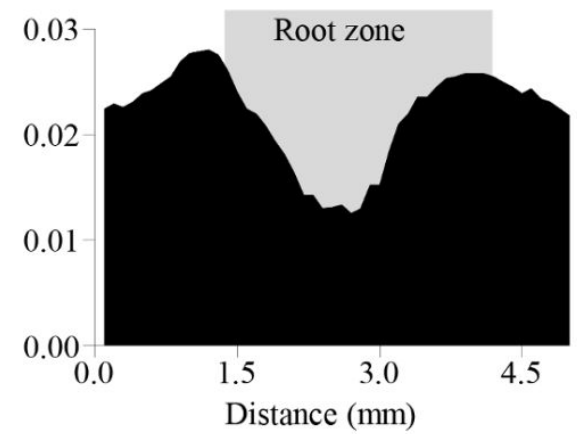

Figure 4. Two-dimensional visualization of $\mathrm{O}_{2}$, As and $P$ in the rice rhizosphere by PF gel. (a) $\mathrm{O}_{2}$ distribution in the whole plant rhizosphere. The horizontal dashed lines show the soil-water interface (SWI). The orange/dash-lined box denotes the location of the DGT deployment. (b) $\mathrm{O}_{2}$ image corresponding with element imaging. $\mathrm{O}+\mathrm{R}$ indicates aerobic rhizosphere, O-B indicates non-rhizosphere/anaerobic bulk soil, FM denotes the flux maxima from the root apex associated rhizosphere. (c) As (d) P. The $0,5 /$ bar marker shows the distance of the horizontal axes on plot (e) and (f). (e) Root As flux transect (red line; subplot d). The grey shading denotes the location of the root apex associated rhizosphere. (f) Root P flux transect (along the red line). The grey shading denotes the location of the root apex associated rhizosphere. The metal fluxes ( $f_{\text {DGT }}, \mathrm{pg} \mathrm{cm}^{-2} \mathrm{~s}^{-1}$ ) and oxygen concentration (percent air saturation) on the $2 \mathrm{D}$ images increased sequentially with the color scale shown from blue to white. The scales in the figure represent the following ranges from $0 \%$ to $100 \%$ for $\mathrm{O}_{2}$, from 0.016 to 0.378 for As, and from 0.003-0.041 for P. 
(a) Element concentrations in subsoils

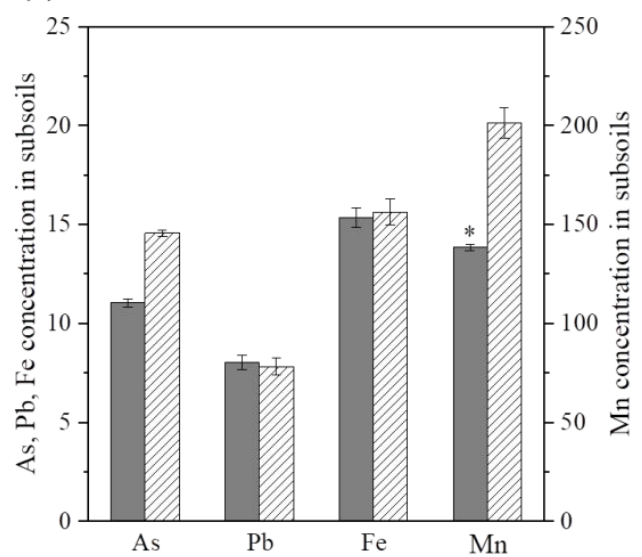

(b) Element concentrations in porewater

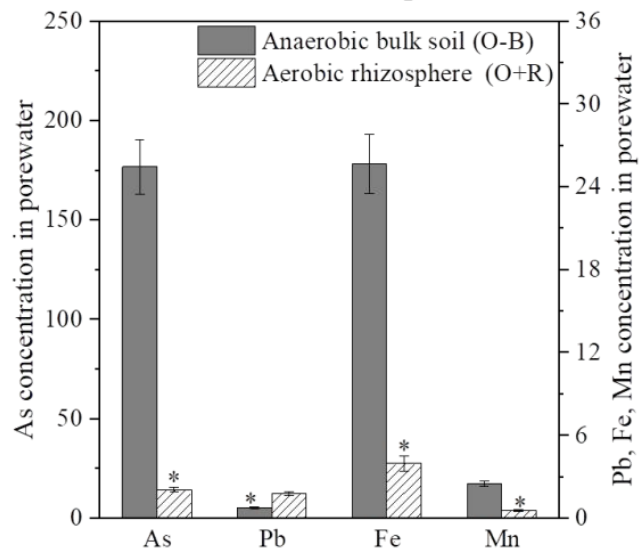

Figure 5. Concentrations of $\mathrm{As}, \mathrm{Pb}, \mathrm{Fe}$ and $\mathrm{Mn}$ in subsoils (a) and porewater (b) from anaerobic bulk/field zone $(\mathbf{O}-\mathrm{B})$ and rhizosphere aerobic zone $(\mathbf{O}+\mathbf{R})$. The error bars are from the standard error of 6 replicates. Note the concentration units- unit of Fe in subsoils is $\mathrm{g} \mathrm{kg}^{-1}, \mathrm{As}, \mathrm{Pb}$, and $\mathrm{Mn}$ in subsoils is $\mathrm{mg} \mathrm{kg}^{-1}$. The unit of $\mathrm{Fe}$ and $\mathrm{Mn}$ in porewater is $\mathrm{mg} \mathrm{l}^{-1}$, As and $\mathrm{Pb}$ in porewater is $\mu \mathrm{g} \mathrm{l}^{-1}$. The asterisks (*) denote significant difference at $p<0.05$ evaluated by one-way analysis of variance followed by Duncan's multiple range test between bulk anaerobic media and rhizosphere aerobic zone. 